\title{
Hematologic Malignancies in Pregnancy: Management Guidelines From an International Consensus Meeting
}

Michael Lishner, Irit Avivi, Jane F. Apperley, Daan Dierickx, Andrew M. Evens, Monica Fumagalli, Irena Nulman, Fuat S. Oduncu, Fedro Alessandro Peccatori, Susan Robinson, Kristel Van Calsteren, Tineke Vandenbroucke, Frank Van den Heuvel, and Frederic Amant

Michael Lishner, Meir Medical Center, Kfar Saba, and Tel Aviv University; Irit Avivi, Ichilov Medical Center, Tel Aviv, Israel; Jane F. Apperley, Hammersmith Hospital; Susan Robinson, Guy's and St Thomas' National Health Service Foundation Trust, London; Frank Van den Heuvel, University of Oxford, Oxford, United Kingdom; Andrew M. Evens, Tufts Medical Center, Boston, MA; Monica Fumagalli, University of Milan; Fedro Alessandro Peccatori, European Institute of Oncology, Milan, Italy; Irena Nulman, University of Toronto, and The Hospital for Sick Children, Toronto, Ontario, Canada; Fuat S. Oduncu, University of Munich, Munich, Germany; Kristel Van Calsteren University Hospital Gasthuisberg; Tineke Vandenbroucke and Frederic Amant, Katholieke Universiteit Leuven; Daan Dierickx, University of Leuven; and Tineke Vandenbroucke, University Hospitals

Leuven, Leuven, Belgium.

Published online ahead of print at www.jco.org on November 30, 2015.

Authors' disclosures of potential conflicts of interest are found in the article online at www.jco.org. Author contributions are found at the end of this article.

Corresponding author: Michael Lishner, Department of Medicine A, Meir Medica Center, 59 Tshernichovsky St, Kfar Saba 44281, Israel; e-mail:michael2@clalit. org.il.

(C) 2015 by American Society of Clinical Oncology

0732-183X/16/3405w-501w/\$20.00

DOI: 10.1200/JCO.2015.62.4445

\section{$\begin{array}{llllllll}\text { A } & \text { B } & \mathbf{S} & \mathbf{T} & \mathbf{R} & \mathbf{A} & \mathbf{C} & \mathbf{T}\end{array}$}

\section{Purpose}

The incidence of hematologic malignancies during pregnancy is $0.02 \%$. However, this figure is increasing, as women delay conception until a later age. Systemic symptoms attributed to the development of a hematologic cancer may overlap with physiologic changes of pregnancy. A favorable prognosis is contingent upon early diagnosis and treatment. Therefore, a high index of suspicion is required by health care providers. Although timely, accurate diagnosis followed by appropriate staging is essential and should not be delayed due to pregnancy, management guidelines are lacking due to insufficient evidence-based research. Consequently, treatment is delayed, posing significant risks to maternal and fetal health, and potential pregnancy termination. This report provides guidelines for clinical management of hematologic cancers during the perinatal period, which were developed by a multidisciplinary team including an experienced hematologist/oncologist, a high-risk obstetrics specialist, a neonatologist, and experienced nurses, social workers, and psychologists.

\section{Methods}

These guidelines were developed by experts in the field during the first International Consensus Meeting of Prenatal Hematologic Malignancies, which took place in Leuven, Belgium, on May 23, 2014.

\section{Results and Conclusion}

This consensus summary equips health care professionals with novel diagnostic and treatment methodologies that aim for optimal treatment of the mother, while protecting fetal and pediatric health.

\section{J Clin Oncol 34:501-508. (C) 2015 by American Society of Clinical Oncology}

\section{RATIONALE AND GOALS FOR A CONSENSUS MEETING}

Although uncommon, the diagnosis of a hematologic malignancy during pregnancy is a dramatic, traumatic event for the patient, her family, and the medical team, raising therapeutic, ethical, and social dilemmas. The rarity of this event precludes prospective, controlled trials; most available information is based on retrospective cohorts, observations, and case reports. Therefore, it is essential to incorporate current knowledge, expert experience, and information on emerging medications and treatment approaches to provide comprehensive guidelines for managing these patients.

An international consensus panel was organized to review diagnostic and novel therapeutic approaches and to integrate new information into treatment protocols for pregnant women with hematologic cancers. Participants were identified based on scientific and clinical contributions to the field. Researchers and clinicians who focus on the teratogenic, obstetric, and neonatal aspects of cancer therapy were also approached. Each member contributed a section that was merged into a draft, which was circulated to all participants before the meeting in Leuven, Belgium, on May 23, 2014. The draft was revised based on consensus achieved during the meeting. It was then circulated to all authors and revised until final consensus was reached.

\section{GUIDELINES FOR DIAGNOSTIC PROCEDURES} INCLUDING IMAGING

Diagnosing a hematologic malignancy encompasses a range of techniques. Pregnancy poses special precautions for their use.

Peripheral lymph node and bone marrow biopsies can be performed safely. Although general anesthesia is considered safe, when it is necessary, the risks and benefits should be weighed carefully. 
Abdominal and pelvic imaging for lymphoma staging should rely on nonionizing magnetic resonance imaging (MRI) and ultrasonography techniques, excluding cone-beam computed tomography (CT).

Irradiation-related fetal toxicity seems to occur when fetal exposure exceeds $100 \mathrm{mSv} .^{1}$ The radiation exposure associated with chest $\mathrm{x}$-rays and CT examinations is significantly lower than the fetotoxic threshold. ${ }^{2}$ However, pelvic and abdominal CT are prohibited due to high fetal exposure. Fluorodeoxyglucose positron emission tomography is not recommended, because it results in pelvic irradiation and placental transfer of $\left[{ }^{18} \mathrm{~F}\right]$ fluorodeoxyglucose, which is considered fetotoxic. ${ }^{3}$

MRI is an important diagnostic tool. Although there is no evidence of harmful fetal effects, many regulatory bodies discourage the use of gadolinium-based compounds during pregnancy due to concerns regarding radiofrequency field and acoustic damage. ${ }^{4}$ Recent reviews suggest that MRI can be performed for selected indications. ${ }^{5}$ Gadobenate dimeglumine (MultiHance, Bracco Pharma, Milan, Italy) and gadoterate meglumine (Dotarem, Guerbet LLC, Bloomington, IN) are safer than gadolinium, because they are not associated with nephrogenic systemic fibrosis, although studies evaluating their general safety are required.

Although abdominal and pelvic ultrasound are less sensitive than MRI, they are often used as inexpensive, safe, and widely available alternatives during pregnancy. Imaging should be used judiciously, taking into consideration the proposed technique, imaging field, and gestational stage.

\section{GUIDELINES FOR CHEMOTHERAPY}

The teratogenic potential of any drug depends on the extent of placental transfer, dose, duration and timing of exposure, and genetic variations in maternal and fetal drug metabolism. Chemotherapy during the first trimester can increase the risk of spontaneous abortion, fetal death, and major malformations by $10 \%$ to $20 \%{ }^{6}$

The embryo is extremely vulnerable to drug-related teratogenicity during organogenesis (weeks 2 to 8 of gestation). However, some organs and systems, including the eyes, genitalia, hematopoietic system, and CNS, remain vulnerable throughout pregnancy.

The fetal phase (ie, second and third trimesters) is characterized by growth and functional maturation of already formed organs and systems. During this phase, the impact of chemotherapy is less predictable. Although the risk of malformation is decreased, risks of intrauterine growth retardation, preterm delivery, and low birth weight are increased. ${ }^{8}$ Hematopoietic suppression and subclinical renal or cardiac dysfunction have been reported, although rarely.

A limited number of drugs are proven human teratogens and are contraindicated during pregnancy. Older-generation alkylators (procarbazine, busulfan, chlorambucil, and nitrogen mustard) have high teratogenic and abortive potential; whereas anthracyclines and vinca alkaloids (vinblastine, vincristine) have the lowest. ${ }^{9}$ The antimetabolites aminopterin and methotrexate are teratogenic, whereas cytarabine has lower fetotoxic potential. Thalidomide causes phocomelia and CNS dysmorphology at a frequency of $15 \%$ to $100 \%$, particularly when taken 27 to 50 days postconception. Lenalidomide and pomalidomide, the new immunomodulating agents, are also considered teratogenic based on their effect on rats and on the thalidomide experience in humans. ${ }^{10}$ Tretinoin (known as all-trans-retinoic acid [ATRA]) is associated with cardiac, craniofacial, and neurologic malformations (retinoid embryopathy) in up to $85 \%$ of cases, if taken during the first trimester. ${ }^{9,11}$

The increasing use of targeted anticancer therapies has complicated the choice of treatment for pregnant patients because safety data are lacking. Incorporating these new tools during pregnancy is questionable in some instances and contraindicated in others. A plethora of animal studies showed increased teratogenicity with most new drugs. The most common of these, rituximab and the tyrosine kinase inhibitors (TKIs), are discussed in detail within the context of their relevant diseases. Intermediate- to high-dose corticosteroids are often used as bridging therapy, providing symptom management for non-Hodgkin lymphoma (NHL) and Hodgkin lymphoma (HL), especially during the first trimester.

\section{GUIDELINES FOR RADIOTHERAPY}

Treatment of hematologic malignancies is based primarily on chemotherapeutic and biologic agents, whereas radiotherapy is usually used in combination with chemotherapy for HL and NHL. The decision to administer radiotherapy in a prenatal setting is complex. Fetal exposure may cause malformations, growth retardation, and death. Long-term adverse effects, including mental retardation, sterility, and cataracts resulting from cell death due to irreparable DNA damage, are possible, as is childhood cancer, which is thought to arise from incomplete repair of damaged DNA.

The preponderance and severity of these effects depend strongly on fetal dose and gestational stage. Risks of malformation, growth retardation, and mental retardation are highest during the embryonic, organogenesis, and early fetal phases. Hence, radiotherapy is generally contraindicated during the first 15 weeks postconception except under rare circumstances. ${ }^{12}$ After that time, the decision depends on individual factors, including radiation energy, modality and volume, proximity to the fetus, and treatment technique. It must be considered that even at later stages, exposure to doses $\geq 100 \mathrm{mSv}$ (especially $\geq 500 \mathrm{mSv}$ ) is associated with increased risks of malformation and mental retardation. After 25 weeks, $\leq 1 \mathrm{~Sv}(1000$ $\mathrm{mSv}$ ) is considered relatively safe, depending on the radiation site. ${ }^{13}$

The probability of childhood cancer is dose dependent, regardless of gestational stage at exposure. A dose of $100 \mathrm{mSv}$ generates a $1 \%$ increase in cancer incidence in a population. ${ }^{14,15}$

A medical physicist should be consulted regarding the estimated fetal dose. Current clinical planning systems are not optimal for estimating doses outside the treatment area. Alternatives such as Monte Carlo simulations ${ }^{16}$ or other measurements ${ }^{17}$ should be considered.

When the estimated dose is above $100 \mathrm{mSv}$, an informed decision to treat needs to be made with the patient, using dosimetry analyses provided by the medical physicist. Even if the estimated dose is low, it should be reduced as much as possible in accordance with the ALARA (as low as reasonably acceptable) principle.

The choices of therapeutic modality and technique are important for achieving a low incidental dose. Electron-based treatments generate less scattered dose, but are impractical because they are for superficial targets. Photon-based treatments 
need to be limited to lower energies $(<10 \mathrm{MV})$ to avoid neutron generation. Newer conformal techniques increase the dose outside the target volume and should be used cautiously. Protons and carbon ions promise an even lower incidental dose and could be future modalities of choice. ${ }^{18}$

The total dose includes leakage from the head of the radiation device and scattered radiation from the treatment room as well as from inside the patient. The patient should have additional protection against leakage and room scatter. Protective lead aprons should be avoided and patient-specific shielding using bridge construction and/or tertiary shield walls should be used instead. ${ }^{19}$

In summary, irradiation is not recommended during pregnancy. However, use of involved field irradiation to locations distant from the fetus, ensuring minimal fetal exposure, is an option, taking into consideration gestational stage and the unique clinical scenario.

\section{MATERNAL SUPPORTIVE CARE}

Chemotherapy complications include nausea, vomiting, allergic reactions, and high risk of infections due to disease- and treatmentinduced neutropenia. Antiemetics, including D2 receptor antagonists (metoclopramide $)^{20}$ and serotonin receptor antagonists (ondansetron), ${ }^{21}$ are considered safe.

A review of antibiotic use during pregnancy is beyond the scope of this paper. Generally, aminoglycosides, trimethoprim, and tetracyclines should not be prescribed, whereas macrolides, cephalosporins, penicillin, and metronidazole are probably safe. ${ }^{22}$

The administration of granulocyte growth factors is probably safe, but data are limited. ${ }^{23}$ Blood and blood products can be transfused safely. ${ }^{3}$

Pregnancy is a hypercoagulable state in which cancer and chemotherapy administration can increase the risk of venous thromboembolism and placental thrombosis. Low molecular weight heparins (LMWHs), which do not cross the placenta, are effective and can be used prophylactically and therapeutically. ${ }^{24}$

\section{CLINICAL CHARACTERISTICS AND MANAGEMENT OF} HEMATOLOGIC MALIGNANCIES

\section{Lymphoma}

$\mathrm{HL}$ is the most common hematologic cancer during pregnancy, followed by NHL. Diagnosis is often delayed because symptoms mimic those accompanying pregnancy (eg, shortness of breath, fatigue, and night sweats) and imaging studies are obtained infrequently. Chest x-ray, MRI, and ultrasonography are usually used for investigation and disease staging.

\section{$H L$}

Few patients diagnosed with HL present with asymptomatic, early stage IA/B or IIA nonmediastinal disease. ${ }^{25}$ In these cases, treatment may be deferred until after delivery, especially if diagnosis is established during the third trimester.

However, most cases require early antepartum treatment. When HL is diagnosed during the first trimester, a regimen based on vinblastine monotherapy followed by classic ABVD (doxorubicin, bleomycin, vinblastine, dacarbazine) therapy postpartum, or in case of progression, has been used. ${ }^{26}$ However, this approach has not been validated by other groups. ${ }^{27}$ The limited data available suggest that ABVD may be administered safely and effectively during the latter phases of pregnancy. Although it may be associated with prematurity and lower birth weights, studies have not reported significant disadvantages. ${ }^{25,28}$

Nonpregnant patients with advanced-stage HL (stage IIB, III, or IV) are typically treated with extended courses of multiagent chemotherapy (ABVD or BEACOPP [bleomycin, etoposide, doxorubicin, cyclophosphamide, vincristine, procarbazine, and prednisone]), with or without involved-field radiotherapy. ${ }^{29}$ As in early stage HL, ABVD can be given during the second and third trimesters. Information about the use of BEACOPP during pregnancy is not available. However, given the higher dose of anthracyclines and the inclusion of alkylating agents in this regimen, it should be avoided. Also, caution is advised regarding use of supplemental oxygen if bleomycin has been administered. Brentuximab vedotin administered during organogenesis caused embryofetal lethality and teratogenicity in animals; consequently, the product was assigned Pregnancy Category D (ADCETRIS package insert; Takeda Italia, Cerano, Italy).

The prognosis for women diagnosed with HL during pregnancy seems excellent. They have similar long-term survival compared with matched, nonpregnant controls. ${ }^{30}$

\section{NHL}

The evaluation and management of NHL during pregnancy is complex, partly due to the pathologic and clinical heterogeneity of the disease. Important considerations include establishing a histologic diagnosis, appropriate staging with assessment of tumor burden, type and timing of therapy, and timing of delivery. ${ }^{31,32}$

Identifying the histologic subtype is an important initial step. ${ }^{25}$ A recent, retrospective series described characteristics and outcomes of 50 patients with NHL during pregnancy. ${ }^{25}$ The most common subtype was diffuse large B-cell lymphoma, constituting 73\% of B-cell NHLs and $56 \%$ of all NHLs. Notably, $20 \%$ of patients had T-cell lymphoma, all of which were peripheral/mature T-cell NHLs.

Despite suboptimal staging (eg, absence of functional imaging such as positron emission tomography), studies of NHL during pregnancy have shown a high incidence of extranodal involvement. ${ }^{33-35}$ Moreover, atypical extranodal sites (vagina, breast, and ovary) are often encountered. ${ }^{35}$

Table 1 summarizes the recommended management of NHL during pregnancy. The decision to administer antenatal therapy is based on several factors, such as type of NHL (indolent $v$ aggressive), gestational age, and patient preference. Asymptomatic patients with low tumor burden, indolent NHL may be observed, whereas aggressive subtypes warrant systemic therapy in most patients. However, labor should not be induced to expedite chemotherapy. An overarching goal in the care of all pregnant patients with NHL is delivery at term. ${ }^{36}$ Combination chemotherapy, although relatively safe during the second and third trimesters, ${ }^{37,38}$ is contraindicated in early gestational stages.

NHLs warranting antimetabolite therapy (primary CNS lymphoma and Burkitt's lymphoma) are challenging. ${ }^{39,40}$ Aggressive chemotherapy regimens including antimetabolites during pregnancy have been reported. However, caution is advised regarding 


\begin{tabular}{|c|c|c|}
\hline Hematologic Malignancy & Stage of Pregnancy* & Suggested Approach \\
\hline Indolent non-Hodgkin lymphoma (eg, FL) & Early and late & $\begin{array}{l}\text { Watchful waiting. } \\
\text { Treat if symptomatic and/or evidence of disease progression, } \\
\text { using monoclonal antibodies with or without chemotherapy. } \\
\text { Steroids can be administered during the first trimester as a } \\
\text { bridge to the second trimester, when chemotherapy can be } \\
\text { used with relatively greater safety. }\end{array}$ \\
\hline Aggressive lymphomas & $\begin{array}{l}\text { Early } \\
\text { Late }\end{array}$ & $\begin{array}{l}\text { Pregnancy termination and administration of therapy. } \\
\text { Treat as nonpregnant woman, including monoclonal antibodies } \\
\text { (R-CHOP). }\end{array}$ \\
\hline Highly aggressive lymphoma requiring CNS prophylaxis & $\begin{array}{l}\text { Up to } 20 \text { weeks } \\
\text { After } 20 \text { weeks }\end{array}$ & $\begin{array}{l}\text { Pregnancy termination and administration of therapy. } \\
\text { Adequate combination regimen including high-dose } \\
\text { methotrexate. }\end{array}$ \\
\hline Hodgkin lymphoma & Late & $\begin{array}{l}\text { Postpone treatment to second trimester, if possible. If not } \\
\text { possible, pregnancy termination and administration of } \\
\text { therapy. } \\
\text { Treat as nonpregnant woman. }\end{array}$ \\
\hline
\end{tabular}

fetal teratogenicity (methotrexate [MTX] syndrome and myelosuppression $^{41}$ ). Hence, they are not recommended, especially before week 20 of gestation.

Rituximab, an IG1 $\kappa$ monoclonal antibody, is a backbone of B-cell NHL treatment. It crosses the placenta via a specific, receptormediated mechanism. Recent studies suggest transplacental passage increases with gestational age. A retrospective, observational study reported a 58\% (90/153) live birth rate after rituximab exposure in utero. $^{42}$ The first trimester miscarriage rate was $21 \%$; most occurred when chemotherapy was coadministered. Twenty-two (24\%) infants were born prematurely; 11 of them had transient neutropenia, thrombocytopenia, or B-cell depletion at birth (not clinically significant). Two infants had congenital anomalies (one clubfoot and one cardiac malformation), suggesting that rituximab is not obviously associated with increased incidence of malformation or infection.

\section{Chronic Myeloid Leukemia}

Chronic myeloid leukemia (CML) occurs in approximately 1 of 100,000 pregnancies. ${ }^{43}$ It is often diagnosed during routine blood testing when the patient is completely asymptomatic. Weight loss, abdominal bloating, and night sweats, which are characteristics of CML, can also be attributed to pregnancy. The diagnosis can be confirmed by the presence of the $t(9 ; 22)$ cytogenetic abnormality and/or the fusion oncogene, $B C R-A B L 1$; both can be detected using bone marrow and blood samples.

The introduction of TKIs into clinical practice has changed the outcome of CML dramatically. Approximately $90 \%$ of patients can expect to have significant, long-lasting responses and tolerate at least one of the five available TKIs. Unfortunately, TKIs are contraindicated during pregnancy. TKIs inhibit $B C R-A B L 1$, together with several other tyrosine kinases including $\mathrm{c}$-kit, the platelet-derived growth factor receptors $\alpha$ and $\beta$, arg, c-fms, and in the case of dasatinib and bosutinib, Src and Src-related kinases. Some of these proteins, particularly platelet-derived growth factor receptor $\alpha$, are important for embryonic implantation, gonadal development, and fetal maturation and should thus be avoided. ${ }^{44}$

A survey of 180 fetuses exposed to imatinib (57\% during organogenesis) identified a higher than expected incidence of skeletal malformations (eg, premature closure of skull sutures, craniosynostosis, absent hemivertebrae, shoulder anomalies, and scoliosis), as well as renal (eg, duplex kidney, agenesis), respiratory (eg, hypoplastic lungs), and gastrointestinal (eg, exomphalos, omphalocele) abnormalities. ${ }^{45}$ Exomphalos was almost 1,000-fold higher than expected. Most women had discontinued imatinib when or soon after pregnancy was confirmed, which suggests that the effects of TKIs occur during the first trimester. Nevertheless, almost $70 \%$ of pregnancies that were not electively terminated resulted in the delivery of normal, healthy infants. Some physicians treat pregnant CML patients from the second trimester, ${ }^{46}$ resulting in a lower risk of malformations, although this is not recommended by the drug manufacturers.

Because CML might have been diagnosed later had the patient not been under maternity care, treatment may not be needed until the white count and/or platelet count have risen to levels associated with the onset of symptoms. An approximate guideline is white cell count greater than $100 \times 10^{9} / \mathrm{L}$ and platelet count greater than $500 \times 10^{9} / \mathrm{L}$. Therapeutic approaches other than TKIs should be considered, including leukapheresis and interferon- $\alpha$ (IFN- $\alpha$ ). Leukapheresis can be effective in decreasing cell counts; however, it is frequently required two to three times per week during the first and second trimesters. Counts tend to drop during the third trimester, allowing less frequent intervention. ${ }^{46}$

IFN- $\alpha$ does not inhibit DNA synthesis and is considered safe in pregnancy, based on animal studies and case reports. ${ }^{47-49}$ IFN- $\alpha$ is a high molecular weight molecule and should not cross the placenta. It should be remembered that when IFN- $\alpha$ was first-line therapy for CML, it did not always induce good hematologic control and was often supplemented with hydroxycarbamide, a cytotoxic agent that inhibits RNA synthesis. It is known to cause embryotoxicity, including craniofacial and spinal defects, in many animal species, ${ }^{50}$ but seems to be less damaging than expected in humans. In a series of five pregnancies in which hydroxycarbamide was continued throughout gestation, four infants were unaffected and one pregnancy resulted in the stillbirth of a morphologically normal fetus at 26 weeks. ${ }^{51}$

Consideration should be given to adding aspirin and/or LMWH when the platelet count is $>1000 \times 10^{9} / \mathrm{L}$, due to increased risk for 
thrombosis. The next section on myeloproliferative neoplasms contains a detailed discussion on thrombotic risks and management.

For women who present in accelerated phase, the disease pace needs to be carefully monitored and advice offered accordingly. In cases of CML in blast crisis during early pregnancy (which remains an aggressive phase of the disease with a poor prognosis, regardless of TKI therapy), recommended management is similar to that of acute leukemia.

\section{Myeloproliferative Neoplasms}

This section focuses on essential thrombocytosis (ET), polycythemia vera (PV), and primary myelofibrosis (PMF). The incidence of myeloproliferative neoplasms (MPN) is six of 100,000 to 10 of 100,000 annually. Diagnosis is usually during the sixth or seventh decade of life. However, ET, in particular, peaks in women of reproductive age. Fifteen percent of patients with PV are younger than 40 years of age at diagnosis.

ET is the most common MPN in women of childbearing age. A large meta-analysis of pregnant women with ET reported a live birth rate of $50 \%$ to $70 \%$, first trimester loss in $25 \%$ to $40 \%$, late pregnancy loss in $10 \%$, placental abruption in $3.6 \%$, and intrauterine growth restriction in $4.5 \% .{ }^{52}$ Maternal morbidity is rare, but stroke has been reported. ${ }^{53}$ Although limited, literature regarding PV and PMF is concordant. ${ }^{54,55}$

Hydroxycarbamide (hydroxyurea) and anagrelide should be stopped before conception, with an adequate wash-out period. In the event of a clear indication for cytoreductive therapy, IFN- $\alpha$ should be considered.

Box 1 lists factors that define high-risk pregnancies in women with MPN, based upon clinical experience. Analysis of outcomes in pregnant women with ET suggests that JAK2 V617F increases the risk of loss. ${ }^{56}$ However, the strength of the association is not sufficient to recommend an alternative management strategy.

Management of low-risk pregnancy. Low-dose aspirin is safe and advantageous in MPN. ${ }^{56,57}$ Unless clearly contraindicated, aspirin (75 mg per day) should be offered throughout pregnancy. For women with PV, venesection may be continued when tolerated to maintain the hematocrit within the gestation-appropriate range.

Fetal ultrasound scans should be performed at 20,26, and 34 weeks of gestation and uterine artery Doppler should be performed at 20 weeks of gestation. If the mean pulsatility index exceeds 1.4, the pregnancy may be considered high risk and treatment and monitoring should be increased. ${ }^{58,59}$

Management of high-risk pregnancy. In high-risk pregnancies, additional treatment includes cytoreductive therapy \pm LMWH. If cytoreductive therapy is required, INF- $\alpha$ should be titrated to maintain a platelet count of less than $400 \times 10^{9} / \mathrm{L}$ and hematocrit within appropriate range.

Local protocols regarding interruption of LMWH should be adhered to during labor, and dehydration should be avoided. Of note, platelet count and hematocrit may increase postpartum, requiring cytoreductive therapy. Thromboprophylaxis should be considered 6 weeks postpartum due to increased risk of thrombosis. ${ }^{52}$

\section{Acute Leukemia}

Acute leukemia, reported in one of 75,000 to one of 100,000 pregnancies, ${ }^{60-62}$ presents multiple medical and ethical challenges.

\section{Box 1. Criteria for High-Risk Myeloproliferative Neoplasms During Pregnancy}

Sustained rise in platelet count less than $1500 \times 109 /$ L. $^{*}$ Previous venous or arterial thrombosis.

Previous occurrence of one or more hemorrhages attributed to myeloproliferative neoplasms. ${ }^{*}$

Previous pregnancy complications:

a. Unexplained death of a morphologically normal fetus 10 weeks of gestation or older.

b. At least one premature delivery of a morphologically normal fetus at less than 34 weeks of gestation due to:

i. Severe preeclampsia or eclampsia defined according to standard criteria.

ii. Recognized features of placental insufficiency.

c. Three or more unexplained consecutive miscarriages at less than 10 weeks of gestation, without anatomic, hormonal, or chromosomal abnormalities.

d. Otherwise unexplained intrauterine growth restriction.

e. Significant antepartum or postpartum hemorrhage requiring transfusion.

Abnormal uterine artery Doppler at week 20 of gestation (mean pulsatility index $>1.4$ ).

${ }^{\star}$ Indication for interferon only, rather than interferon plus low molecular weight heparin.

The remarkable anemia, thrombocytopenia, and neutropenia that characterize acute myeloid and lymphoblastic leukemia and impair maternal health and fetal development. ${ }^{63}$ Prompt treatment is mandatory. Leukapheresis in the presence of clinically significant evidence of leukostasis can be considered, regardless of gestational stage. ${ }^{63}$ For patients diagnosed with acute myeloid leukemia (AML) during the first trimester, pregnancy termination followed by conventional induction therapy (cytarabine/anthracycline) is recommended. Those diagnosed later can receive conventional induction therapy, although this seems to be associated with increased risk of fetal growth restriction and even fetal loss. Notably, neonates rarely experience neutropenia and cardiac impairment unless exposed to lipophilic idarubicin, which should not be used. ${ }^{64,65}$

Acute promyelocytic leukemia presents a unique scenario in the setting of AML. It is often accompanied by disseminated intravascular coagulation. ATRA, a backbone of acute promyelocytic leukemia therapy, induces differentiation of leukemic cells, but is highly teratogenic during the first trimester. ${ }^{1,66}$ Therefore, pregnancy termination is recommended before conventional ATRA-anthracycline therapy. ${ }^{11}$ It demonstrates low teratogenicity after the first trimester and can be used then. ${ }^{66}$ Arsenic treatment is highly teratogenic and prohibited throughout gestation. ${ }^{66}$

Although it presents challenges similar to those of AML, acute lymphocytic leukemia (ALL) raises additional therapeutic issues. It requires prophylactic CNS therapy, including MTX and L-asparaginase, which are fetotoxic. ${ }^{67,68}$ MTX interferes with 


\begin{tabular}{|c|c|c|c|c|c|}
\hline Corticosteroid & $\begin{array}{l}\text { Equivalent } \\
\text { Dose, mg* }\end{array}$ & $\begin{array}{c}\text { Anti-Inflammatory } \\
\text { Potencyt }\end{array}$ & $\begin{array}{c}\text { Biologic } \\
\text { Half-Life, Hours }\end{array}$ & $\begin{array}{l}\text { Placental } \\
\text { Transfer }\end{array}$ & $\begin{array}{c}\text { Placental } \\
\text { Metabolism }\end{array}$ \\
\hline Cortisone & 31 & 0.8 & $8-12$ & Efficient & Extensive \\
\hline Hydrocortisone & 25 & 1 & 8-12 & Efficient & Extensive \\
\hline Prednisone & 6 & 4 & $12-36$ & Efficient & Extensive \\
\hline Prednisolone & 6 & 4 & $12-36$ & Poor & Extensive \\
\hline Triamcinolone & 5 & 5 & $12-36$ & Efficient & Resistant \\
\hline Methylprednisolone & 5 & 5 & $12-36$ & Poor & Extensive \\
\hline Betamethasone & 1 & 25 & $36-72$ & Efficient & Resistant \\
\hline Dexamethasone & 1 & 25 & $36-72$ & Efficient & Resistant \\
\hline
\end{tabular}

organogenesis and is prohibited before week 20 of gestation. ${ }^{3,41}$ L-asparaginase may increase the high risk for thromboembolic events attributed to the combination of pregnancy and malignancy. Notably, TKIs, essential for patients with Philadelphia chromosome-positive ALL, are teratogenic. ${ }^{45}$ Given these limitations, women diagnosed with ALL before week 20 of gestation should undergo termination of the pregnancy and conventional treatment. After week 20, conventional chemotherapy can be administered during pregnancy and TKIs postpartum.

Leukemia transfer to the fetus seems remarkably low. ${ }^{69}$ This may be due to a highly protective placental barrier or the elimination of leukemic cells by the immune system. ${ }^{70}$

See Appendix (online only) on rare hematologic malignancies, including hairy cell leukemia, multiple myeloma, and myelodysplastic syndromes.

\section{PERINATAL AND PEDIATRIC ASPECTS}

Maternal hematologic malignancies are associated with miscarriages, thromboembolism, as well as impaired nutrient exchange, blood flow, and oxygen delivery in the intervillous placental spaces due to leukemia cells. This leads to higher rates of fetal growth restriction, premature birth, and perinatal mortality.

Cytotoxic treatment can increase perinatal risks. ${ }^{7,71,72}$ Transient neonatal myelosuppression, a rare complication, is seen after chemotherapy or rituximab administration near term (ie, after week 34 of gestation). ${ }^{73}$ To avoid such outcomes, a 3-week interval between drug administration and anticipated delivery should be planned to avoid accumulation of cytotoxins in the neonate. ${ }^{74}$

Accumulating prospective research has not found an association between corticosteroids and increased rates of congenital anomalies. Retrospective reports found a small absolute risk for clefting dysmorphology. ${ }^{75}$ Synthetic corticosteroids cross the placenta in varying amounts $^{76}$ and differ significantly in their ability to enter the fetal circulation. ${ }^{77-80}$ Therefore, those that cross the placenta in smaller amounts, such as prednisolone and methylprednisolone, should be chosen. However, a dose-dependent effect has been observed and use should be limited to the smallest effective dose for the shortest duration. Table 2 includes a summary of these effects.

Fetal growth and morphology should be monitored with ultrasound. The placenta should be examined for metastases, primarily with leukemia and melanomas. ${ }^{81}$ Placental metastasis necessitates disease upstaging and careful fetal monitoring. Neonates should be assessed by a dysmorphologist and geneticist, and followed up by a pediatrician for physical health, potential cardiotoxicity, pediatric cancer, long-term neurodevelopment, and future fertility.

The varying results produced by studies on the potential cardiotoxicity of anthracyclines indicate a need for additional research. Gziri et $\mathrm{al}^{82}$ reported lower normal fractional shortening and mildly thinner left ventricular wall, but normal ejection fraction in children exposed prenatally. However, Avilés and colleagues ${ }^{83,84}$ reported normal cardiac morphology and function in 81 children during 17 years of follow-up.

No association was found between prenatal diagnostic radiation and increased rates of childhood and other cancers in more than 2,000,000 exposed children. ${ }^{85,86}$ Exposure in early infancy has been associated with increased risk for lymphomas (odds ratio 5.14; 95\% CI 1.27 to 20.78). ${ }^{87}$ However, considering the wide CI, these findings require replication. The benefits of a timely, accurate maternal diagnosis should be weighed against the low risk of childhood mutagenicity.

Research on long-term neurodevelopment of children exposed to chemotherapy is sparse, but reassuring. ${ }^{88}$ Avilés and $\mathrm{Neri}^{84}$ found no cognitive, neurologic, or psychologic abnormalities in 84 children prenatally exposed to maternal chemotherapy during 18.7 years of follow-up. Normal fertility and cognitive abilities were documented in 12 second-generation children. ${ }^{84}$ However, a recent prospective study found a 2.5-point decrease in IQ associated with each week of prematurity in children exposed to chemotherapy. ${ }^{89}$ Iatrogenic prematurity should be avoided to prevent impaired neurodevelopment. With the possible exception of acute leukemia, delivery should be at term, whenever possible. ${ }^{90}$

The safety of breastfeeding during chemotherapy should be evaluated based on maternal health and medications used. The LactMed Web site and neonatologist breastfeeding experts should be consulted. When in doubt, breastfeeding is not advised. ${ }^{91}$

In conclusion, although hematologic malignancies in pregnancy are rare, they introduce clinical, social, ethical, and moral dilemmas to the patient, their family, and physicians. The therapeutic challenge is to preserve maternal health and survival without endangering fetal well-being. Evidence-based data are scarce and collaborative efforts are needed to increase the number of clinical and basic research studies. A multidisciplinary team-including, at minimum, an experienced hematologist/oncologist, a high-risk obstetrics specialist, a neonatologist, as well as experienced nurses, 
social workers, and psychologists, providing close follow-up-is critical to ensuring optimal maternal and fetal outcomes.

The International Network on Cancer, Infertility and Pregnancy registers all cancers occurring during gestation (www.cancerinpregnancy.org). Patient accrual is ongoing and essential, because registration of new cases and long-term follow-up will improve clinical knowledge and increase the level of evidence.

\section{AUTHORS' DISCLOSURES OF POTENTIAL CONFLICTS OF INTEREST}

Disclosures provided by the authors are available with this article at www.jco.org.

\section{AUTHOR CONTRIBUTIONS}

Conception and design: Michael Lishner, Irena Nulman, Kristel Van

Calsteren, Frederic Amant

Financial support: Frederic Amant

Administrative support: Michael Lishner

Collection and assembly of data: Michael Lishner, Irit Avivi, Jane F. Apperley, Andrew M. Evens, Monica Fumagalli, Fuat S. Oduncu, Fedro A. Peccatori, Susan Robinson, Kristel Van Calsteren, Tineke Vandenbroucke, Frank Van den Heuvel, Frederic Amant

Data analysis and interpretation: Michael Lishner, Irit Avivi, Jane F. Apperley, Daan Dierickx, Andrew M. Evens, Irena Nulman, Fuat S. Oduncu, Fedro A. Peccatori, Susan Robinson, Kristel Van Calsteren, Tineke Vandenbroucke, Frank Van den Heuvel, Frederic Amant

Manuscript writing: All authors

Final approval of manuscript: All authors

\section{REFERENCES}

1. Wang $\mathrm{PI}$, Chong ST, Kielar $\mathrm{AZ}$, et al: Imaging of pregnant and lactating patients: part 1, evidencebased review and recommendations. AJR Am J Roentgenol 198:778-784, 2012

2. Woussen S, Lopez-Rendon X, Vanbeckevoort $D$, et al: Clinical indications and radiation doses to the conceptus associated with $\mathrm{CT}$ imaging in pregnancy: A retrospective study. Eur Radiol 10.1007/s00330 01503924-8 [epub ahead of print on July 23, 2015]

3. Brenner B, Avivi I, Lishner M: Haematological cancers in pregnancy. Lancet 379:580-587, 2012

4. Bulas $D$, Egloff $A$ : Benefits and risks of $M R I$ in pregnancy. Semin Perinatol 37:301-304, 2013

5. Patenaude Y, Pugash D, Lim K, et al: Diag nostic Imaging Committee; Society of Obstetricians and Gynaecologists of Canada: The use of magnetic resonance imaging in the obstetric patient. J Obstet Gynaecol Can 36:349-363, 2014

6. Doll DC, Ringenberg QS, Yarbro JW: Man agement of cancer during pregnancy. Arch Intern Med 148:2058-2064, 1988

7. Cardonick E, lacobucci A: Use of chemotherapy during human pregnancy. Lancet Oncol 5:283-291, 2004

8. Pereg D, Lishner M: Maternal and fetal effects of systemic therapy in the pregnant woman with cancer. Recent Results Cancer Res 178:21-38, 2008

9. Azim HA Jr., Pavlidis N, Peccatori FA: Treatment of the pregnant mother with cancer: a systematic review on the use of cytotoxic, endocrine, targeted agents and immunotherapy during pregnancy. Part II: Hematologica tumors. Cancer Treat Rev 36:110-121, 2010

10. Smith D, Stevens J, Quinn J, et al: Myeloma presenting during pregnancy. Hematol Oncol 32 52-55, 2014

11. Lammer EJ, Chen DT, Hoar RM, et al: Retinoic acid embryopathy. N Engl J Med 313:837-841, 1985

12. Streffer $C$, Shore $R$, Konermann $G$, et al: Biological effects after prenatal irradiation (embryo and fetus). A report of the International Commission on Radiological Protection. Ann ICRP 33:5-206, 2003

13. Otake $M$, Schull WJ: Radiation-related brain damage and growth retardation among the prenatally exposed atomic bomb survivors. Int J Radiat Biol 74 159-171, 1998

14. International Commission on Radiological Protection: Pregnancy and medical radiation. Ann ICRP 30:iii-viii, 1-43, 2000
15. National Research Council Committee to Assess Health Risks from Exposure to Low Levels of Ionizing Radiation. Health risks from exposure to low levels of ionizing radiation: BEIR VII Phase 2. Washington, DC, National Academies Press, 2006

16. Bednarz $B, X u X G$ : Monte Carlo modeling of a 6 and $18 \mathrm{MV}$ Varian Clinac medical accelerator for infield and out-of-field dose calculations: development and validation. Phys Med Biol 54:N43-N57, 2009

17. D'Agostino $E$, Bogaerts $R$, Defraene $G$, et al: Peripheral doses in radiotherapy: A comparison between IMRT, VMAT and tomotherapy. Radiat Meas 57:62-67, 2013

18. La Tessa $C$, Berger $T$, Kaderka $R$, et al: Out-of-field dose studies with an anthropomorphic phantom: comparison of X-rays and particle therapy treatments. Radiother Oncol 105:133-138, 2012

19. Stovall $M$, Blackwell $C R$, Cundiff J, et al: Fetal dose from radiotherapy with photon beams: report of AAPM Radiation Therapy Committee Task Group No. 36. Med Phys 22:63-82, 1995 [Erratum: Med Phys 22:1353-1354, 1995]

20. Matok I, Gorodischer R, Koren G, et al: The safety of metoclopramide use in the first trimester of pregnancy. N Engl J Med 360:2528-2535, 2009

21. Einarson A, Maltepe C, Navioz Y, et al: The safety of ondansetron for nausea and vomiting of pregnancy: A prospective comparative study. BJOG 111:940-943, 2004

22. Einarson A, Shuhaiber S, Koren G: Effects of antibacterials on the unborn child: What is known and how should this influence prescribing. Paediatr Drugs 3:803-816, 2001

23. Dale DC, Cottle TE, Fier CJ, et al: Severe chronic neutropenia: treatment and follow-up of patients in the Severe Chronic Neutropenia International Registry. Am J Hematol 72:82-93, 2003

24. Greer IA, Nelson-Piercy C: Low-molecularweight heparins for thromboprophylaxis and treatment of venous thromboembolism in pregnancy: a systematic review of safety and efficacy. Blood 106: 401-407, 2005

25. Evens AM, Advani R, Press OW, et al: Lymphoma occurring during pregnancy: Antenatal therapy, complications, and maternal survival in a multicenter analysis. J Clin Oncol 31:4132-4139, 2013

26. Bachanova V, Connors JM: How is Hodgkin lymphoma in pregnancy best treated? ASH Education Program Book 2008.1:33-34, 2008

27. Connors JM: Challenging problems: Coincident pregnancy, HIV infection, and older age. ASH Education Program Book 2008.1:334-339, 2008
28. Van Calsteren $K$, Heyns $L$, De Smet $F$, et al: Cancer during pregnancy: An analysis of 215 patients emphasizing the obstetrical and the neonatal outcomes. J Clin Oncol 28:683-689, 2010

29. Borchmann $P$, Eichenauer DA, Engert A: State of the art in the treatment of Hodgkin lymphoma. Nat Rev Clin Oncol 9:450-459, 2012

30. Lishner M, Zemlickis D, Degendorfer $\mathrm{P}$, et al: Maternal and foetal outcome following Hodgkin's disease in pregnancy. $\mathrm{Br} J$ Cancer 65:114-117, 1992

31. Kwee TC, Vermoolen MA, Akkerman EA, et al: Whole-body $\mathrm{MRI}$, including diffusion-weighted imaging, for staging lymphoma: Comparison with CT in a prospective multicenter study. J Magn Reson Imaging 40:26-36, 2014

32. Zanotti-Fregonara P, Koroscil TM, Mantil J, et al: Radiation dose to the fetus from [(18)F]-FDG administration during the second trimester of pregnancy. Health Phys 102:217-219, 2012

33. Wang $\mathrm{PH}$, Chao $\mathrm{KC}$, Lin $\mathrm{G}$, et al: Primary malignant lymphoma of the cervix in pregnancy. A case report. J Reprod Med 44:630-632, 1999

34. Kirkpatrick AW, Bailey DJ, Weizel HA: Bilateral primary breast lymphoma in pregnancy: A case report and literature review. Can J Surg 39:333-335, 1996

35. Horowitz NA, Benyamini N, Wohlfart K, et al: Reproductive organ involvement in non-Hodgkin lymphoma during pregnancy: A systematic review. Lancet Oncol 14:e275-e282, 2013

36. Amant F, Han SN, Gziri MM, et al: Management of cancer in pregnancy. Best Pract Res Clin Obstet Gynaecol 29:741-753, 2015

37. Lishner M, Zemlickis D, Sutcliffe SB, et al: Non-Hodgkin's lymphoma and pregnancy. Leuk Lymphoma 14:411-413, 1994

38. Zemlickis $D$, Lishner $M$, Degendorfer $P$, et al: Fetal outcome after in utero exposure to cancer chemotherapy. Arch Intern Med 152:573-576, 1992

39. Lam MS: Treatment of Burkitt's Iymphoma during pregnancy. Ann Pharmacother 40:2048-2052, 2006

40. Peterson C, Lester DR, Jr., Sanger W: Burkitt's lymphoma in early pregnancy. J Clin Oncol 28: e136-e138, 2010

41. Hyoun SC, Običan SG, Scialli AR: Teratogen update: Methotrexate. Birth Defects Res A Clin Mol Teratol 94:187-207, 2012

42. Chakravarty EF, Murray ER, Kelman AJ, et al: Pregnancy outcomes after maternal exposure to rituximab. Blood 117:1499-1506, 2011 
43. Apperley JF: Chronic myeloid leukaemia. Lancet 385:1447-1459, 2015

44. Nurmio M, Kallio J, Toppari J, et al: Adult reproductive functions after early postnatal inhibition by imatinib of the two receptor tyrosine kinases, c-kit and PDGFR, in the rat testis. Reprod Toxicol 25: 442-446, 2008

45. Pye SM, Cortes J, Ault $P$, et al: The effects of imatinib on pregnancy outcome. Blood 111:5505-5508, 2008

46. Milojkovic D, Apperley JF: How I treat leukemia during pregnancy. Blood 123:974-984, 2014

47. Harrison C: Pregnancy and its management in the Philadelphia negative myeloproliferative diseases. Br J Haematol 129:293-306, 2005

48. Yazdani Brojeni P, Matok I, Garcia Bournissen $F$, et al: A systematic review of the fetal safety of interferon $\alpha$. Reprod Toxicol 33:265-268, 2012

49. Griesshammer M, Struve S, Barbui T: Management of Philadelphia negative chronic myeloproliferative disorders in pregnancy. Blood Rev 22:235-245, 2008

50. Thauvin-Robinet $\mathrm{C}$, Maingueneau $\mathrm{C}$, Robert $\mathrm{E}$, et al: Exposure to hydroxyurea during pregnancy: $A$ case series. Leukemia 15:1309-1311, 2001

51. Barbui T, Finazzi G: Myeloproliferative disease in pregnancy and other management issues. Hematology (Am Soc Hematol Educ Program) 2006: 246-252, 2006

52. Griesshammer M, Grünewald M, Michiels $\mathrm{JJ}$ : Acquired thrombophilia in pregnancy: Essential thrombocythemia. Semin Thromb Hemost 29: 205-212, 2003

53. Willoughby SJ, Fairhead S, Woodcock BE, et al: Postpartum thrombosis in primary thrombocythaemia. Eur J Haematol 59:121-123, 1997

54. Robinson S, Bewley S, Hunt BJ, et al: The management and outcome of 18 pregnancies in women with polycythemia vera. Haematologica 90:1477-1483, 2005

55. Tulpule S, Bewley S, Robinson SE, et al: The management and outcome of four pregnancies in women with idiopathic myelofibrosis. Br J Haematol 142:480-482, 2008

56. Passamonti F, Randi $M L$, Rumi $E$, et al: Increased risk of pregnancy complications in patients with essential thrombocythemia carrying the JAK2 (617V>F) mutation. Blood 110:485-489, 2007

57. Gangat N, Wolanskyj AP, Schwager S, et al: Predictors of pregnancy outcome in essential thrombocythemia:A single institution study of 63 pregnancies. Eur J Haematol 82:350-353, 2009

58. Cnossen JS, Morris RK, ter Riet G, et al: Use of uterine artery Doppler ultrasonography to predict preeclampsia and intrauterine growth restriction: A systematic review and bivariable meta-analysis. CMAJ 178:701-711, 2008

59. Llurba E, Carreras E, Gratacós E, et al: Maternal history and uterine artery Doppler in the assessment of risk for development of early- and late-onset preeclampsia and intrauterine growth restriction. Obstet Gynecol Int 2009:275613, 2009

60. Yahia C, Hyman GA, Phillips LL: Acute leukemia and pregnancy. Obstet Gynecol Surv 13:1-21, 1958

61. Catanzarite VA, Ferguson JE, II. Acute leukemia and pregnancy: A review of management and outcome, 1972-1982. Obstet Gynecol Surv 39:663-678, 1984

62. Haas JF: Pregnancy in association with a newly diagnosed cancer: A population-based epidemiologic assessment. Int J Cancer 34:229-235, 1984

63. Abadi U, Koren G, Lishner M: Leukemia and lymphoma in pregnancy. Hematol Oncol Clin North Am 25:277-291, 2011

64. Reynoso EE, Huerta F: Acute leukemia and pregnancy-fatal fetal outcome after exposure to idarubicin during the second trimester. Acta Oncol 33:709-710, 1994

65. Koren G, Pastuszak A, Ito S: Drugs in pregnancy. N Engl J Med 338:1128-1137, 1998

66. Sanz MA, Grimwade D, Tallman MS, et al: Management of acute promyelocytic leukemia: Recommendations from an expert panel on behalf of the European LeukemiaNet. Blood 113:1875-1891, 2009

67. Sanfeliu C, Nebot-Cegarra J, Domenech-Mateu JM: Teratogenic effects of $\mathrm{L}$-asparaginase in rat embryos in vitro. Acta Anat (Basel) 125:152-160, 1986

68. Sherer DM, Dalloul M, Santoso $P$, et al: Complete abortion of a nonviable cervical pregnancy following methotrexate treatment. Am J Perinatol 21: 223-226, 2004

69. Osada S, Horibe K, Oiwa K, et al: A case of infantile acute monocytic leukemia caused by vertica transmission of the mother's leukemic cells. Cancer 65:1146-1149, 1990

70. Decker $\mathrm{M}$, Went $\mathrm{P}$ : Placental barrier in acute myeloid leukemia. Br J Haematol 145:553, 2009

71. Amant F, von Minckwitz G, Han SN, et al: Prognosis of women with primary breast cancer diagnosed during pregnancy: Results from an international collaborative study. J Clin Oncol 31:2532-2539, 2013

72. Avilés $A$, Neri N, Nambo MJ: Hematological malignancies and pregnancy: Treat or no treat during first trimester. Int J Cancer 131:2678-2683, 2012

73. Udink ten Cate FE, ten Hove $\mathrm{CH}$, Nix WM, et al: Transient neonatal myelosuppression after fetal exposure to maternal chemotherapy. Case reportand review of the literature. Neonatology 95:80-85, 2009

74. Chelghoum Y, Vey N, Raffoux E, et al: Acute leukemia during pregnancy: A report on 37 patients and a review of the literature. Cancer 104:110-117, 2005

75. Park-Wyllie L, Mazzotta P, Pastuszak A, et al: Birth defects after maternal exposure to corticosteroids: Prospective cohort study and meta-analysis of epidemiological studies. Teratology 62:385-392, 2000

76. Diederich $S$, Eigendorff $E$, Burkhardt $P$, et al: $11 \beta$-Hydroxysteroid dehydrogenase types 1 and 2 : An important pharmacokinetic determinant for the activity of synthetic mineralo- and glucocorticoids. J Clin Endocrinol Metab 87:5695-5701, 2002
77. Beitins IZ, Bayard $F$, Ances IG, et al: The transplacental passage of prednisone and prednisolone in pregnancy near term. J Pediatr 81:936-945, 1972

78. Ballard PL, Granberg P, Ballard RA: Glucocorticoid levels in maternal and cord serum after prenatal betamethasone therapy to prevent respiratory distress syndrome. J Clin Invest 56:1548-1554, 1975

79. Moore LE, Martin JN Jr: When betamethasone and dexamethasone are unavailable: Hydrocortisone. J Perinatol 21:456-458, 2001

80. Rennick GJ: Use of systemic glucocorticosteroids in pregnancy: Be alert but not alarmed. Australas J Dermatol 47:34-36, 2006

81. Alexander A, Samlowski WE, Grossman $D$ et al: Metastatic melanoma in pregnancy: Risk of transplacental metastases in the infant. J Clin Onco 21:2179-2186, 2003

82. Gziri MM, Hui W, Amant F, et al: Myocardial function in children after fetal chemotherapy exposure. A tissue Doppler and myocardial deformation imaging study. Eur J Pediatr 172:163-170, 2013

83. Avilés $A$, Neri $N$, Nambo MJ: Long-term evaluation of cardiac function in children who received anthracyclines during pregnancy. Ann Oncol 17: 286-288, 2006

84. Avilés A, Neri N: Hematological malignancies and pregnancy: A final report of 84 children who received chemotherapy in utero. Clin Lymphoma 2 173-177, 2001

85. Doll R, Wakeford R: Risk of childhood cancer from fetal irradiation. Br J Radiol 70:130-139, 1997

86. Ray JG, Schull MJ, Urquia ML, et al: Major radiodiagnostic imaging in pregnancy and the risk of childhood malignancy: A population-based cohort study in Ontario. PLoS Med 7:e1000337, 2010

87. Rajaraman P, Simpson J, Neta G, et al: Early life exposure to diagnostic radiation and ultrasound scans and risk of childhood cancer: Case-control study. BMJ 342:d472, 2011

88. Cardonick $E H$, Gringlas $M B$, Hunter $K$, et al: Development of children born to mothers with cancer during pregnancy: comparing in utero chemotherapyexposed children with nonexposed controls. Am Obstet Gynecol 212:658.e1-658.e8, 2015

89. Amant $F$, Van Calsteren $K$, Halaska MJ, et al: Long-term cognitive and cardiac outcomes after prenatal exposure to chemotherapy in children aged 18 months or older: An observational study. Lancet Oncol 13:256-264, 2012

90. Amant $F$, Halaska MJ, Fumagalli $M$, et al: ESGO Task Force 'Cancer in Pregnancy': Gynecologic cancers in pregnancy: Guidelines of a second international consensus meeting. Int J Gynecol Cancer 24:394-403, 2014

91. Pistilli $B$, Bellettini $G$, Giovannetti $E$, et al: Chemotherapy, targeted agents, antiemetics and growth-factors in human milk: How should we counsel cancer patients about breastfeeding. Cancer Treat Rev 39:207-211, 2013 


\section{AUTHORS' DISCLOSURES OF POTENTIAL CONFLICTS OF INTEREST}

Hematologic Malignancies in Pregnancy: Management Guidelines From an International Consensus Meeting

The following represents disclosure information provided by authors of this manuscript. All relationships are considered compensated. Relationships are self-held unless noted. I = Immediate Family Member, Inst = My Institution. Relationships may not relate to the subject matter of this manuscript. For more information about ASCO's conflict of interest policy, please refer to www.asco.org/rwc or jco.ascopubs.org/site/ifc.

\section{Michael Lishner}

No relationship to disclose

\section{Irit Avivi}

No relationship to disclose

Jane F. Apperley

Consulting or Advisory Role: Ariad, Bristol-Myers Squibb, Novartis, Pfizer

Speakers' Bureau: Ariad, Bristol-Myers Squibb, Novartis, Pfizer

Research Funding: Novartis

Travel, Accommodations, Expenses: Pfizer, Novartis, Bristol-Myers Squibb

\section{Daan Dierickx}

No relationship to disclose

\section{Andrew M. Evens}

Honoraria: Seattle Genetics, Genentech, Celgene, Millennium

Consulting or Advisory Role: Celgene, Millennium

Speakers' Bureau: Genentech, Celgene

Research Funding: Millennium

Monica Fumagalli

No relationship to disclose
Irena Nulman

No relationship to disclose

Fuat S. Oduncu

No relationship to disclose

Fedro A. Peccatori

No relationship to disclose

\section{Susan Robinson}

Honoraria: Novartis

Kristel Van Calsteren

No relationship to disclose

Tineke Vandenbroucke

No relationship to disclose

Frank Van den Heuvel

No relationship to disclose

Frederic Amant

No relationship to disclose 


\section{Acknowledgment}

The International Consensus Meeting of Prenatal Hematologic Malignancies was sponsored by the European Society of Gynecologic Oncology. J.F.A. is grateful for the support of the National Institute for Health Research Biomedical Research Centre. The manuscript was edited by Faye Schreiber.

\section{Appendix}

\section{Rare Hematologic Malignancies}

Hairy cell leukemia. Hairy cell leukemia during pregnancy is extremely rare, with few cases reported (Williams JK: Am J Obstet Gynecol 156:210-211, 1987; Alothman A, et al: Ann Intern Med 120:1048-1049, 1994; Rizack T, et al: Am J Hematol 84:830-841, 2009; Daver N, et al: Clin Lymphoma Myeloma Leuk 13:86-89, 2013). Management includes supportive measures and specific treatments. Cladribine, the treatment of choice, is not recommended during pregnancy, because it is associated with teratogenicity and fetal bone marrow suppression. Nevertheless, cladribine was administered in late pregnancy in one case only, without fetal harm (Daver N, et al: Clin Lymphoma Myeloma Leuk 13:86-89, 2013). In general, interferon $\alpha$ (Baer MR, et al: Br J Haematol 81: $167-169,1992)$ and rituximab ${ }^{28}$ are preferred for the treatment of hairy cell leukemia during pregnancy, and splenectomy may be considered (Alothman A, et al: Ann Intern Med 120:1048-1049, 1994; Stiles GM, et al: J Perinatol 18:200-201, 1998; Adeniji BA, et al: Case Rep Med pii:136823 2010; Bustamante A, et al: Rev Med Chil 138:1422-1426, 2010).

Multiple myeloma. The incidence of multiple myeloma during pregnancy is rare, with 32 cases reported (Cabanas-Perianes $\mathrm{V}$, et al: Hematol Oncol 2014, doi:10.1002/hon.2184). Thalidomide is a known teratogen. There is no information on bortezomib and lenalidomide, and they are contraindicated during pregnancy. ${ }^{3}$ In contrast, corticosteroids are considered safe during pregnancy and may be used as a bridge until administration of definitive postpartum treatment. ${ }^{10}$ For treating skeletal events such as lytic lesions or fractures, only scant information regarding the safety of bisphosphonate use during pregnancy is available. Use of bisphosphonates should be based on risk-benefit considerations, considering the scant data regarding fetal safety (Djokanovic N, et al: J Obstet Gynaecol Can 30:1146-1148, 2008).

Myelodysplastic syndromes. Myelodysplastic syndromes present clonal marrow stem cell disorders, characterized by ineffective hematopoiesis and blood cytopenias, with potential progression/transformation to acute myeloid leukemia (Adès L, et al: Lancet 383:2239-2252, 2014). Therapeutic options in nonpregnant patients include supportive measures and hypomethylating agents. There are no reports on the use of 5-azacitidine during pregnancy; hence it is not recommended.

Repeated platelet and erythrocyte transfusions can be safely administered (Siddiqui T, et al: Cancer 66:377-381, 1990; Christiaens F, et al: Int J Obstet Anesth 6:270-273, 1997; Hara K, et al: Can J Anaesth 45:157-163, 1998; Steensma DP, et al: Leuk Lymphoma 42:1229-1234, 2001; Ikeda Y, et al: Leuk Res 26:255-260, 2002; Volpicelli P, et al: Leuk Res 32:1605-1607, 2008; Gidiri M, et al: J Obstet Gynaecol 29:665-667, 2009). In some cases, recombinant human erythropoietin was applied after the first trimester with no adverse fetal effects (Harris SA, et al: Obstet Gynecol 87:812-814, 1996; Sackmann Massa F, et al: Leuk Res 33:e23-e25, 2009). Nevertheless, the safety of recombinant human erythropoietin remains uncertain, and use during pregnancy should be minimized. 